\title{
Chemical ecology of the nudibranch Glossodoris pallida: is the location of diet-derived metabolites important for defense?
}

\author{
Conxita Avila*, Valerie J. Paul \\ University of Guam Marine Laboratory, UOG Station, Mangilao, Guam 96923, USA
}

\begin{abstract}
The nudibranch mollusc Glossodoris pallida possesses the diet-derived terpenoid compounds scalaradial, desacetylscalaradial, and deoxoscalarin. In this study, we determined whether the compounds were located strategically in the nudibranch body for defense against predators, as well as whether they were present in mucus secreted by the nudibranch. Analysis of the distribution of metabolites in the different body parts indicated an accumulation of compounds in the border of the mantle (where the mantle dermal formations are located), as well as in the mucus secretion. Several experiments were conducted in order to establish a relationship between the location of the compounds and the chemical defense of the nudibranch, using artificial diets as well as animals with and without the borders of their mantles. The compounds from the mantle border deterred feeding by crabs (Leptodius spp.) and reef fishes when tested at their natural concentrations. When the mantle borders were removed from some nudibranchs, these animals were significantly more susceptible to predation by reef fishes than were animals with their mantle borders intact. While we were able to demonstrate that. the diet-derived compounds in the mantle border function in the defense of the nudibranch, both in the laboratory against the crabs and in the field against natural assemblages of predatory reef fishes, our experiments with artificial diets did not indicate that the location of the compounds was critical for defense. Food cubes with pieces of mantle border tissue or extracts of mantle border tissue distributed uniformly throughout the cubes or along one border were equally effective at deterring feeding by reef fishes relative to control cubes. The location of diet-derived compounds in the mantle borders may also serve other functions in addition to defense.
\end{abstract}

KEY WORDS: Chemical ecology $\cdot$ Nudibranchs $\cdot$ Feeding deterrence - Diet-derived metabolites

\section{INTRODUCTION}

Opisthobranch molluscs, and nudibranchs in particular, contain a wide variety of mostly diet-derived secondary metabolites that are presumably involved in their defense against predators (Karuso 1987, Faulkner 1992 and references therein, Avila 1995). However, few field experiments actually demonstrate that opisthobranchs are protected against putative marine predators that might encounter them in nature (Ros 1976 ,

\footnotetext{
- Present address: Centre d'Estudis Avançats de Blanes, C.S.I.C. Camí de Sta. Bàrbara s/n, E-17300 Blanes (Girona), Spain.E-mail: conxita@ceab.es
}

Paul \& Van Alstyne 1988, Paul et al. 1990, Paul \& Pennings 1991, McClintock et al. 1994, Pennings 1994, Cronin et al. 1995, Rogers et al. 1995).

Nudibranchs obtain chemicals from sponges, cnidarians, bryozoans, and tunicates (Avila 1995 and references therein). The transfer of secondary metabolites from sponges to opisthobranch predators has been recently reviewed (Cimino \& Sodano 1994). It has been hypothesized that the localization of sponge-derived metabolites in the mantles and mucus secretions of nudibranchs is important for chemical defense; however, little experimental evidence supports this hypothesis (Thompson et al. 1982, Pawlik et al. 1988, Avila et al. 1990, 1991, García et al. 1990, Cimino et al. 1993, Fontana et al. 1993). 
<smiles>CC1CCCC2(C)C1CCC1C3CC=C(C=O)C(C=O)C3(C)CCC12</smiles><smiles>CC(=O)OC1CCC2C3(C)CCCC(C)C3CCC2(C)C2CC=C3COC(O)C3CC12</smiles><smiles>CC(=O)OC1CCC2C(CC(O)[C@@H]3C(C)CCCC23C)C2CC=C3COC(O)C3C12C</smiles><smiles>CC1CCCC2(C)C1CCC1C3CC=C(C=O)C(C=O)C3(C)CCC12</smiles>

Fig. 1. Structure of the secondary metabolites of Glossodoris pallida and related nudibranchs: (a) scalaradial, (b) deoxoscalarin, (c) 6-keto-deoxoscalarin, (d) desacetylscalaradial

Chemicals from sponges are accumulated along the mantle border, in mantle dermal formations (MDFs), by several species of chromodorid nudibranchs (Avila et al. 1990, 1991, García et al. 1990, Gavagnin et al. 1992, Fontana et al. 1993, 1994a, b, Avila \& Durfort 1996). There are 3 potential advantages of accumulating diet-derived chemicals in MDFs: (1) maximizing the defensive effects by concentrating the chemicals; (2) avoiding autotoxicity; and (3) concentrating the compounds near the surface to facilitate excretion into the mucus. In the chromodorids, these chemicals are usually accumulated from prey items without being transformed. The only examples of transformation of metabolites in this family of nudibranchs are in Hypselodoris orsini (Glossodoris tricolor; Cimino et al. 1982, 1993), Glossodoris pallida (Rogers \& Paul 1991), Chromodoris funerea (Carté et al. 1986) and Chromodoris youngbleuthi (Terem \& Scheuer 1986). H. orsini transforms scalaradial (a sesterterpene; Fig. 1a) from the sponge Cacospongia mollior into deoxoscalarin, which is found in the viscera. Deoxoscalarin (Fig. 1b) is further transformed into 6-ketodeoxoscalarin (Fig 1c), which is only found in the MDFs (Cimino et al. 1993). The reason for the localization of these different metabolites is not clear.

Glossodoris pallida also possesses sesterterpenes that are obtained from its diet and transformed (Rogers $\&$ Paul 1991). Scalaradial is obtained from the sponge Cacospongia sp., and transformed into deoxoscalarin by the nudibranch (Rogers \& Paul 1991). The location of these metabolites within $G$. pallida has not been previously studied. In addition, previous studies on $G$. pallida (Rogers \& Paul 1991) did not clearly show that these metabolites deterred feeding by reef fishes. In this study, we test the hypothesis that the location of diet-derived compounds in G. pallida is important for defense against potential predators. We ask the following questions: (1) Are the diet-derived compounds strategically located in the $G$. pallida body for defense? (2) Are the metabolites present in mucus secreted by G. pallida? (3) Are the compounds or crude extracts of G. pallida deterrent against crabs and reef fishes at natural concentrations? (4) Is the location of compounds in certain parts of the body important in deterring against both reef fishes and crabs?

\section{METHODS}

Source organisms. The nudibranch Glossodoris pallida (Rüppel \& Leuckart, 1828) and its sponge prey Cacospongia sp. were collected by scuba in Apra Harbor (Guam, Micronesia; $13^{\circ} 25^{\prime} \mathrm{N}, 144^{\circ} 55^{\prime} \mathrm{E}$; Fig. 2) during March and April, 1995, at 21 to $24 \mathrm{~m}$ depth. $G$ pallida, the type species of its genus, is a chromodorid found in Tanzania, the Red Sea and Australia (Rudman 1984). A good description of this white nudibranch can be found in Rudman (1984), who included it in the Chromodoris aureomarginata color-group (Rudman 1985).

The sponge prey had been previously described as Hyrtios erecta (Rogers \& Paul 1991); however, further taxonomic study indicated this assignment was incorrect. The voucher originally examined was dry, giving it the texture and appearance of $H$. erecta. In life, the sponge forms a thick lobate encrustation that is ex-

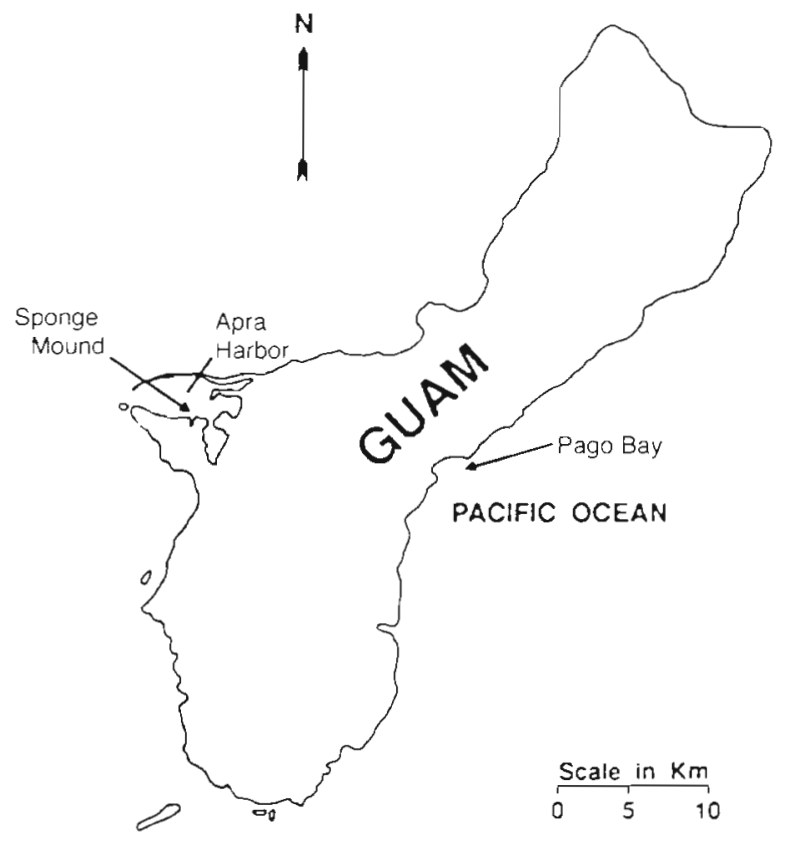

Fig. 2. Map of Guam indicating the sites of collection and field assays 
tremely compressible and easily torn. The surface is highly conulose, with soft, regularly spaced conules, 2 to $3 \mathrm{~mm}$ high; the color in life is gray-black externally, fibers are golden; in ethanol the sponge is deep grayish black, the interior fawn. The skeleton consists of large primary fibers with coring spicule debris masking a granular pith, the secondary fibers are irregular and clear of coring material. The sponge is an undescribed species of Cacospongia (Order Dictyoceratida, Family Thorectidae) (M. Kelly-Borges pers. comm.).

Localization and quantification of metabolites. In order to localize the metabolites in Glossodoris pallida, the animals were carefully dissected into mantle border (containing the MDFs), the rest of the mantle and foot, and viscera. The different sections were extracted separately. The viscera were further dissected and analyzed separately in 1 set of animals, to distinguish between digestive and reproductive systems. A secretion of a white mucus was observed when the specimens were disturbed, and this was also collected.

Chemical analyses of the dissected parts of Glossodoris pallida were conducted with 2 different groups of animals, following standard methods (Rogers \& Paul 1991, Fontana et al. 1994a). Briefly, samples were extracted in acetone, and the organic solvent was rotary evaporated. The dry masses of the nudibranch parts were obtained after extraction. Organic extract yields were calculated from total dry mass of extract plus extracted material. Thin layer chromatography (TLC) was used for qualitative studies and comparisons with authentic samples of known secondary metabolites.

High-performance liquid chromatography (HPLC) was used for quantitative analyses. The retention time and peak size for known amounts of each metabolite were determined under the same solvent and flow rate ( $2 \mathrm{ml} \mathrm{min}{ }^{-1}$ ) conditions. The HPLC consisted of a Beckman model $110 \mathrm{~B}$ solvent pump with an Alltech $25 \mathrm{~cm}$ long $\times 4.6 \mathrm{~mm}$ inner diameter Econosphere $5 \mathrm{U}$ silica column. The injection loop was $20 \mu \mathrm{l}$ in size. All samples were first filtered through a small plug of silica gel in a glass pipet with $25 \%$ ethyl acetate $/ 75 \%$ hexanes to remove polar materials, then diluted to $10 \mathrm{mg} /$ $100 \mu \mathrm{l}$. The mobile phase and dilution solvent was a $25 \%$ ethyl acetate $/ 75 \%$ hexanes mixture, and the injection volume was $10 \mu \mathrm{l}$. Peak areas were measured by automatic electronic integration. Peaks of interest were identified and quantified by injecting a standard at varying concentrations to determine a standard curve. All metabolites isolated by HPLC, including previously identified metabolites and desacetylscalaradial, were further examined by proton nuclear magnetic resonance (NMR) analysis to confirm their structures. Desacety]scalaradial was also acetylated with acetic anhydride in pyridine at room temperature to yield scalaradial for further confirmation of its structure.

The sponge was extracted overnight with acetone. The solvent was evaporated, and the crude extract was used for comparative purposes by TLC, and also to obtain material for field testing

Consumers. The extracts, isolated metabolites, or tissue pieces were tested against 2 different kinds of consumers. Two types of consumers were used because it had been previously observed that different species may respond differently to sponge secondary metabolites (Pennings et al. 1994). The potential consumers used were crabs Leptodius spp. in the laboratory, and natural assemblages of reef fishes in the field. These consumers are considered to be generalist predators.

The fishes that we observed feeding during field assays at Western Shoals $(5 \mathrm{~m}$ depth; Apra Harbor, Guam; Fig. 2) included several species that occur regularly at Apra Harbor such as Amblyglyphidodon curacao, Thalassoma lutescens, Scarus spp., Cheilinus chlorourus, C. fasciatus and Abudefduf sexfasciatus. Each field assay attracted dozens of fish. The crabs were collected at Pago Bay (Guam; Fig. 2) during low tide, under stones. The nudibranchs live in Apra Harbor, and do not occur at Pago Bay at shallow depths; therefore, the crabs and nudibranchs probably do not overlap on a microhabitat scale. Nonetheless, we thought it important to test the nudibranch extracts and tissues against predation by crabs, which tend to be generalist scavengers. We were not able to collect enough crabs for these assays from Apra Harbor, and Leptodius spp. seemed to be suitable species. The fact that these nudibranchs live attached to the sponges they prey upon makes them clearly accessible to crabs and other benthic predators other than fishes.

Feeding assays. Several experiments were conducted in order to determine the importance of the location of the compounds for the effectiveness of the chemical defenses of Glossodoris pallida. Those tests were run in the laboratory with crabs (Leptodius spp.), and in the field with reef fishes at Western Shoals (Fig. 2). Three different kinds of experiments were carried out: (1) experiments with extracts and isolated metabolites incorporated into artificial catfish food cubes; (2) experiments comparing predation on nudibranchs with the mantle border (which contains the MDFs) removed versus intact nudibranchs; and (3) experiments using fresh nudibranch mantle border tissue (containing MDFs) or the extract of MDFs incorporated into artificial squid cube diets.

The effects of the fresh nudibranch tissue, crude extracts of Glossodoris pallida and isolated scalaradial (Fig. 1a) were tested on feeding by incorporating them into artificial food diets. Two types of artificial diets 
were used: catfish food cubes for assays with crabs, and squid cubes for field assays with reef fish. The catfish food consisted of a mixture of carrageenan $(2.5 \mathrm{~g})$, ground catfish food from Kruse Grain and Milling, CA, USA (5 g), shaved paraffin wax (2 g) and tap water $(80 \mathrm{ml})$. The protein content of this diet was approximately $19 \%$, similar to that of the nudibranchs $(20.2 \pm$ $0.3 \%$; mean $\pm \mathrm{SD}_{i} \mathrm{n}=3$ ) (M. Slattery pers. comm.). The ingredients were mixed, heated to boiling, and poured into a mold to form small cubes (about $1 \mathrm{~cm}^{3}$ ). Treatment cubes contained the extracts or isolated compounds dissolved in a small amount of solvent, which was mixed into the recipe after heating. Concentrations of the treated cubes were calculated based on the percent of the metabolite or extract per dry mass of the food cube. Control cubes contained identical amounts of the organic solvent alone.

Squid artificial food cubes for paired field assays (Pennings et al. 1994) were prepared using frozen cubes made with $500 \mathrm{mg}$ (wet mass) of ground squid fillets and $250 \mathrm{ml}$ of tap water that were blended together and poured into ice cube trays. One of these cubes (ca $2 \mathrm{~g}$ dry mass) was mixed with carrageenan $(2.5 \mathrm{~g})$, shaved paraffin wax (2 g), and tap water $(70 \mathrm{ml})$. The mixture was heated, stirred, and poured into the molds. The fresh nudibranch tissue or the extract was incorporated into the cubes before solidifying, as reported below. The cubes were attached with safety pins on ropes (Van Alstyne et al. 1992).

Whole nudibranch extracts and scalaradial were tested only for the crabs, as they had already been tested by Rogers \& Paul (1991) for reef fishes. The 2 treatments tested were whole nudibranch extract at $15 \%$ of dry mass, and scalaradial alone at $2.5 \%$; both of these natural concentrations previously determined by Rogers \& Paul (1991). The crab assays were carried out in small plastic containers (about $30 \mathrm{~cm}$ diameter, $1 \mathrm{~cm}$ water depth), offering 2 catfish food cubes to each crab: 1 control and 1 treatment. In each assay 10 to 12 pairs of cubes were offered to crabs, and another 10 to 12 pairs were left with no crabs. Individual crabs were only tested once and were not reused during the assays. Cubes were removed when half or more of the total was eaten, or after $24 \mathrm{~h}$. Several crabs did not eat any of either cube and were dropped from the analysis. The cubes were weighed before and after the assay to determine the decrease in food mass due to predation. Pairs of cubes were kept in containers with no crabs in order to measure autogenic changes in the mass of food not due to consumption. Data were analyzed following Peterson \& Renaud (1989): the variable '(change in mass of treated food) - (change in mass of control food)' was compared for paired consumer and no-consumer replicates with a paired t-test. To confirm that the metabolites and the extracts did not suffer any transformation during the preparation of the food or during the test itself, samples of cubes were extracted both before and after all the tests, and compared with standards by TLC.

Tests with Glossodoris pallida with and without mantle borders were conducted with both groups of predators. Half of the animals had the border of their mantle removed. The nudibranchs were carefully dissected after a few minutes in the freezer, and only the border of the mantle (a narrow 1 to $2 \mathrm{~mm}$ strip) was removed. Both dissected animals and the intact control nudibranchs were stored frozen until the assay. In the field assays at Western Shoals, the nudibranchs ( $\mathrm{n}=44$ ) were individually dropped randomly into the water column approximately $1 \mathrm{~m}$ above the reef. Nudibranchs with the mantle border removed and intact nudibranchs were observed and scored as eaten or not eaten before reaching the bottom. The species of fishes that mouthed or consumed the nudibranchs were recorded. One nudibranch was lost during the assay. Data were analyzed by a Pearson's chi-squared test. To ensure that wounding the nudibranchs did not stimulate fish feeding, a separate assay was conducted. Reef fishes were offered intact nudibranchs or nudibranchs that were damaged by making several slits in the foot of the nudibranch without cutting the MDFs. Both the intact and damaged nudibranchs were frozen before cutting them and stored frozen until the assay. Live nudibranchs were not used in these assays because of their limited numbers and because they had been previously tested by Rogers \& Paul (1991). In the crab assays, the nudibranchs were held in safety pins and offered paired (1 with mantle border, 1 without mantle border). The test was considered to be finished after the $c r a b$ had eaten one of the items offered. Nudibranchs with and without mantle borders were scored as eaten or not eaten, and the data were analyzed by Fisher's exact test.

Mantle border tissue and the extract mixture representing the border tissue were tested for the fish only, due to limited availability. For the tests with nudibranch tissue, the mantle border was removed as previously described, and then incorporated into the artificial squid food cubes just as the mixture was solidifying Mantle border tissue was placed either along the borders of one face of the food cube ('borders' treatment), or placed uniformly throughout the inside of the cube ('inside' treatment). Squid tissue of a similar size was placed inside the control cubes. The food was designed to be as similar to whole nudibranchs as possible by using nudibranch or squid tissue in the artificial squid diets. The assays were performed in the field at Western Shoals within $2 \mathrm{~h}$ after food cube preparation. Food cubes were 
attached to the ropes by safety pins and were kept refrigerated. Only 1 cube of 1 food type was attached to each rope. A total of 24 groups of 3 ropes each was attached to the reef; the 3 ropes within each group were haphazardly placed 0.1 to $0.25 \mathrm{~m}$ apart in clusters or side by side on the reef, and each group of 3 ropes was placed several meters apart. Several sets of ropes were placed on the reef at one time and the food cubes were often quickly eaten. The ropes were observed constantly for the duration of the assay (usually less than $10 \mathrm{~min}$ per group of 3 ropes). Results were scored as the order in which fish would eat the cubes when offered in groups of 3 (1 control, 1 'inside' treatment, and 1 'borders' treatment rope for each group). Usually all food cubes from the 3 ropes were eventually consumed, but sometimes 1 of the 3 was not eaten by fishes. This experimental design was chosen because the availability of nudibranchs limited the number of cubes we could make. A $G$-test was used to statistically analyze the results in a $3 \times 3$ contingency table (type of food cube $x$ order of consumptionj.

In the tests with extracts, the mixture of MDF extract was used at $12 \%$ dry mass of the artificial squid diet (within the range of natural concentrations; see Table 1), following the same method (borders and inside treatments). The same amount of extract was used for the border and the inside treatments with the difference being that in the border treatment all of the compound was localized along one face of the cube and in the other the extract was evenly distributed throughout the cube. Because of the limited availability of nudibranchs to obtain mantle borders for extraction, we used some border extract and supplemented it with the nonpolar extract of Cacospongia sp. containing the same relative concentrations of scalaradial and desacetylscalaradial (based on TLC and ${ }^{1} \mathrm{H}-\mathrm{NMR}$ ). The sample was injected into the cubes with a microsyringe just as the mixture was cooling. Some of the cubes were injected only along the edges of the upper border while others were injected uniformly throughout the cube. Control cubes were injected with an equivalent amount of solvent. Two cubes per treatment were suspended from each rope by safety pins, and ropes were placed on the reef in groups of 3 (1 rope for each treatment) as described above. Data were scored as number of cubes eaten per treatment when half or more of the cubes were eaten from within each group of 3 ropes (18 replicate groups). A Friedman test was used to analyze the data. The 3 treatments (control, inside, and borders) were the fixed factor and the replicate groups were the random factor for this nonparametric randomized block analysis of variance (ANOVA). Multiple comparisons followed Tukey's procedure for ranked data (Zar 1984).

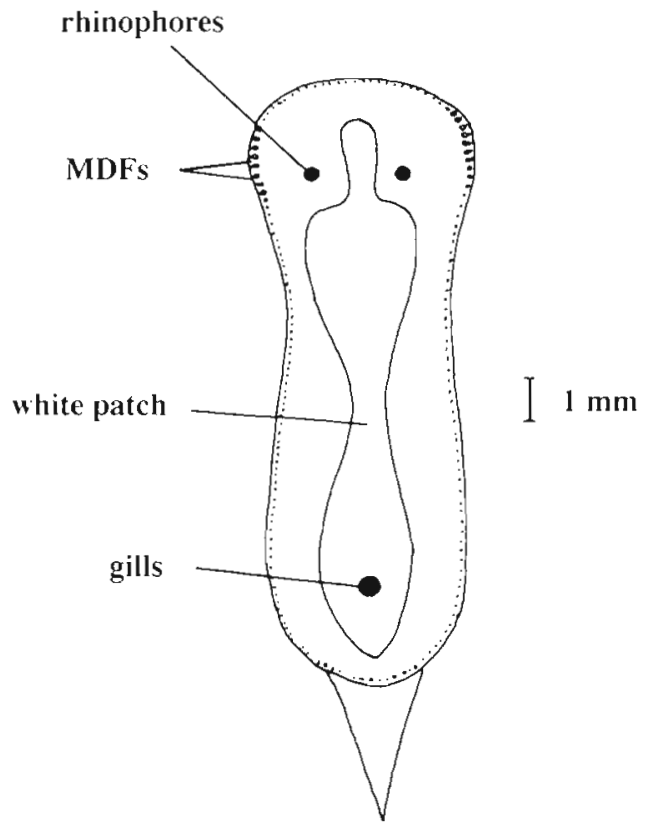

Fig. 3. Location of the mantle dermal formations (MDFs) in the mantle border of Glossodoris pallida

\section{RESULTS}

\section{Localization and quantification of metabolites}

The MDFs in Glossodoris pallida were found to be located along the mantle border as shown in Fig. 3. There were abundant, pear-shaped, opaque white MDFs in the anterior part, close to the rhinophores. Smaller MDFs were observed, with a dissecting scope, all along the lateral and posterior mantle border.

Chemical analyses of the 2 different groups of dissected animals gave qualitatively similar but quantitatively different results (Table 1). The diet-derived metabolites of Glossodoris pallida are selectively distributed in their bodies and white secretion. Quantitative data showed a general pattern of distribution: the 3 main metabolites are present in high concentrations in the border of the mantle (Table 1). Scalaradial (Fig. 1a), the most abundant compound in the mantle borders in both collections (up to $14.6 \%$ dry mass), is scarce in sections other than the mantle border and the secretion, as is desacetylscalaradial (Fig. 1d). Deoxoscalarin is most abundant in the reproductive system/ hermaphroditic gland (up to $10.7 \%$ dry mass), border of the mantle (up to $5.6 \%$ of dry mass), and egg masses $(0.4 \%$ of dry mass) (Table 1). Quantitative differences between the 2 collections of nudibranchs are large. The most likely explanation for this is that we collected and analyzed the secretion in the first collection of animals, which could account for a loss of material 
Table 1 Quantitative distribution of secondary metabolites in the different body parts of Glossodoris pallida, as detected by HPLC. Values reporting $0 \%$ indicate that the peak was not found at the expected retention time and thus was considered to be zero. \% yield was calculated as acetone extract/total dry mass

\begin{tabular}{|c|c|c|c|c|c|}
\hline \multirow[t]{2}{*}{ Section } & \multirow{2}{*}{$\begin{array}{l}\text { Number of anımals } \\
\text { or egg masses }\end{array}$} & \multirow[t]{2}{*}{$\%$ yield } & \multicolumn{3}{|c|}{$\%$ of compound in dry mass } \\
\hline & & & Scalaradial & Deoxoscalarin & Desacetylscalaradial \\
\hline \multicolumn{6}{|l|}{ 1st collection } \\
\hline Border of mantle (MDFs) & 6 & 37.2 & 2.9 & 0.3 & 0.3 \\
\hline Rest of mantle and foot & 6 & 24.9 & 0 & 0.04 & 0 \\
\hline Viscera & 6 & 20.5 & 0 & 0.1 & 0 \\
\hline Egg masses & 5 & 40.9 & 0 & 0.4 & 0 \\
\hline Secretion & 4 & - & Abundant & Absent & Present \\
\hline \multicolumn{6}{|l|}{ 2nd collection } \\
\hline Border of mantle (MDFs) & 4 & 38.8 & 14.6 & 5.6 & 2.2 \\
\hline Rest of mantle and foot & 4 & 24.7 & 0.02 & 0.1 & 0 \\
\hline Digestive gland and ducts & 4 & 31.5 & 0 & 1.7 & 0 \\
\hline \multicolumn{6}{|l|}{ Reproductive system and } \\
\hline hermaphroditic gland & 4 & 31.4 & 0.3 & 10.7 & 0.3 \\
\hline Cacospongia sp. (sponge prey) d & - & - & $2.4^{b}$ & Traces & Abundant \\
\hline
\end{tabular}

from the mantle border. Furthermore, acetone extracts contain water-soluble and more polar materials in addition to the terpenes

\section{Feeding assays}

Crab assays with artificial catfish diet showed that both whole nudibranch extract at $15 \%$ (paired $t$-test. $p=0.01, n=5$ ) and scalaradial at $2.5 \%$ (paired $t$-test, $p<0.001, n=12$ ) deterred feeding (Fig. 4).

In the assays using nudibranchs with and without mantle borders, reef fishes in the field preferentially consumed nudibranchs that were missing the mantle borders (Fig. 5; Pearson's chi-squared, $\mathrm{p}=0.002, \mathrm{n}=$ 43). Amblyglyphidodon curacao, Thalassoma lutescens, Scarus spp., Cheilinus chlorourus, C. fasciatus, and Abudefduf sexfasciatus preferentially ate nudjbranchs with the MDFs removed. A. curacao, T lutescens, and Scarus spp. also ate nudibranchs with the MDFs intact, but intact nudibranchs were not eaten by the wrasses $C$. chlorourus and $C$. fasciatus, nor the sergeant major $A$. sexfasciatus. In all cases, nudibranchs were eaten only after they were mouthed by numerous fishes. In the separate assay with intact nudibranchs and damaged nudibranchs that still retained their MDFs, no difference was observed between the fishes' preference for intact and damaged nudibranchs, but consumption of all nudibranchs was high. Fishes consumed 10 of 14 intact nudibranchs and 13 of 14 damaged nudibranchs ( $p=0.33,2$-tailed Fisher's exact test); however, most nudibranchs were mouthed and rejected by 15 or more fish before they were finally eaten. $A$. curacao, $T$ lutescens, C. fasciatus, and $A$. sexfasciatus consumed both intact and damaged nudibranchs during this assay. Crabs in the laboratory assays showed a similar trend towards consuming more of the nudibranchs with the MDFs removed. Four crabs consumed the nudibranchs with the MDFs removed and avoided nudibranchs with MDFs intact, while

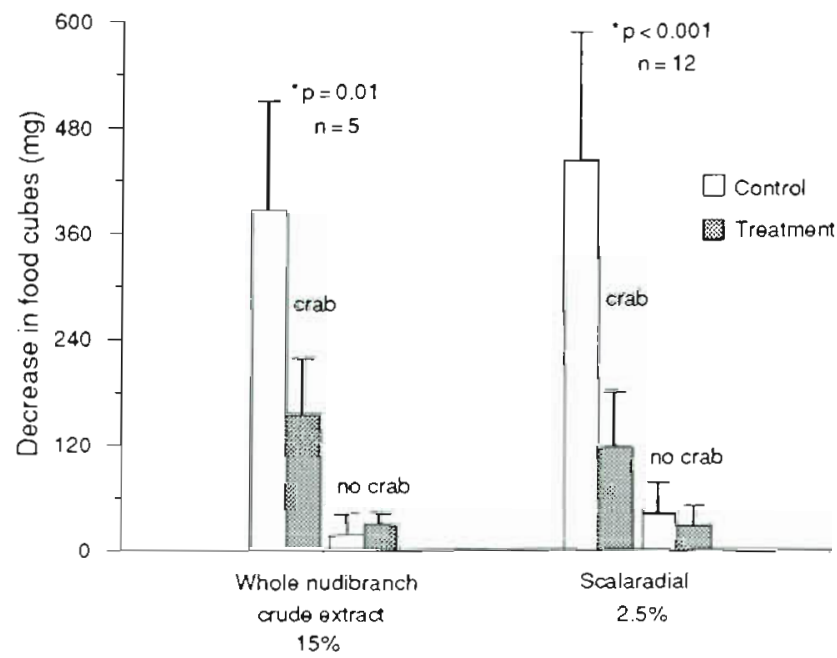

Fig. 4. Results from 2 tests using catfish food cubes to feed crabs, Leptodius spp. The 2 treatments tested were the whole nudibranch extract $115 \%$ dry mass) and scalaradial $(2.5 \%$ dry mass), each against a control (with solvent only). Bars indicate the decrease in mass of food cubes (means + SE) in both treatment and control cubes for both crab and no-crab tests. On top of the bars, the asterisks indicate that both treatments were significantly different from their controls (parred t-test). Probability ( $p$ ) and number of pairs ( $n$ ) used in the test are also indicated 


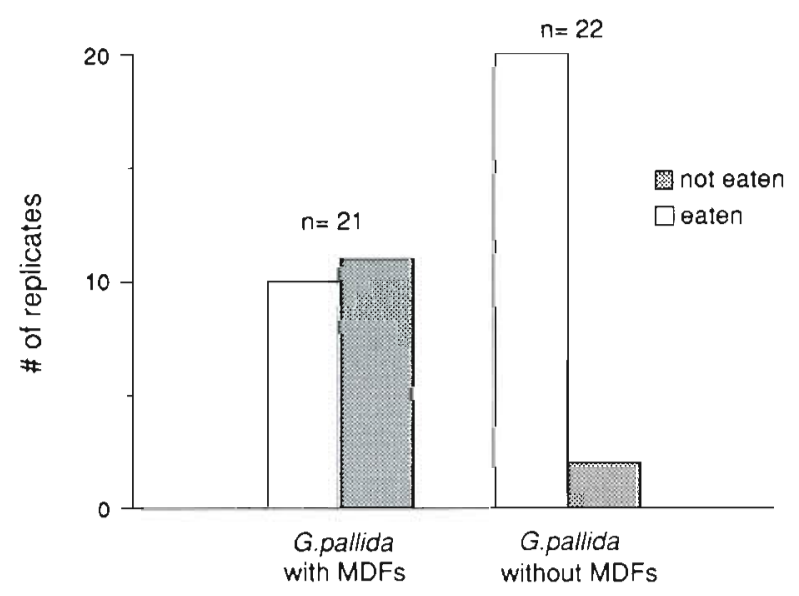

Fig. 5. Reef fish assay in the water column at Western Shoals (Apra Harbor, Guam). Nudibranchs with and without MDFs were used. Bars indicate the number of replicates eaten or not eaten

only 1 crab preferred the nudibranch with the MDFs. However, because of a limited supply of nudibranchs, the sample size was small and these trends were not statistically significant $(p=0.206,2$-tailed Fisher's exact test).

Controls were significantly preferred to both treatments for the assays at Western Shoals with artificial squid diet containing MDF tissue (Fig 6; $3 \times 3$ contingency table, $G$-test, $G=13.88, \mathrm{df}=4, \mathrm{p}<0.01$; unplanned tests of the homogeneity of replicates tested for goodness of fit gave $G=11.14, \mathrm{df}=2, \mathrm{p}<0.05$ and $G=9.05, \mathrm{df}=2, \mathrm{p}<0.05$ for separate comparisons of the 2 treatments with controls). No statistical difference was observed between the 2 treatments with the MDF tissue placed either inside or on the border of the food cubes $(G=0.16$, df $=2, \mathrm{p}>0.90$ ).

In the experiment where the mixture of compounds found in the mantle border was distributed uniformly or only on one border of the artificial squid cubes and compared with controls, consumption differed significantly among the 3 treatments (Fig. 7; $\mathrm{p}=0.013$, Friedman 2-way nonparametric ANOVA). Replicate groups of ropes did not differ significantly (Friedman test, p = 0.998). The control cubes were preferred over the treatment with the compounds uniformly distributed (Fig. 7: Tukey's procedure for ranked data, $p<0.05$ ). The treatment with the mantle border extract located only at the borders was not significantly different from either the control or the uniform treatment (Fig. 7; Tukey's procedure for ranked data). The mixture was tested at $12 \%$ dry mass, a concentration similar to that of the whole body crude extract; however, the natural extract concentration of terpenes in the mantle border can be as high as $22.3 \%$ dry mass (Table 1, 2nd collection).

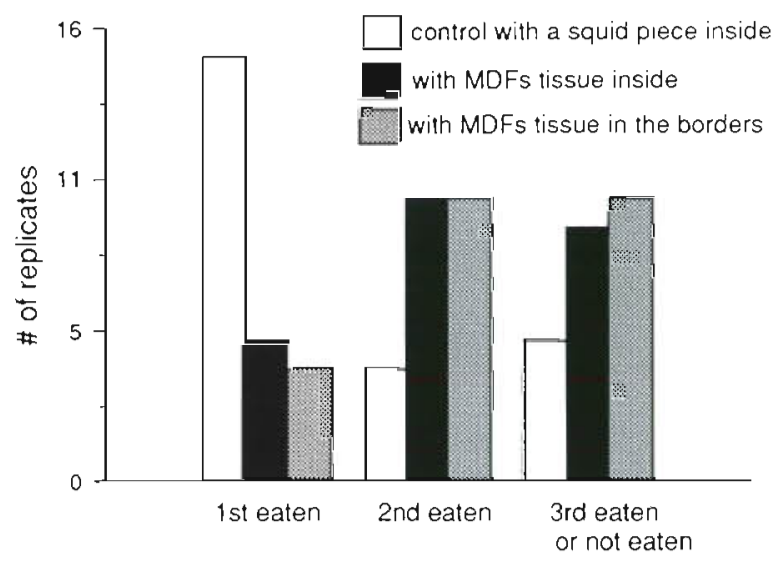

Fig. 6. Reef fish assay with squid cubes on ropes at Western Shoals (Apra Harbor, Guam). Squid cubes were prepared with a piece of squid (control), or with a piece of mantle border from the nudibranchs placed inside the cube, or along one border of the cube. Bars indicate the number of replicates eaten furst, second or last (or not eaten)

\section{DISCUSSION}

The distribution of MDFs in the body of Glossodoris pallida found in this study is similar to that described by Rudman (1984) for specimens from different geographical areas. It also agrees with that described for other chromodorids (Rudman 1984, Avila et al. 1991.

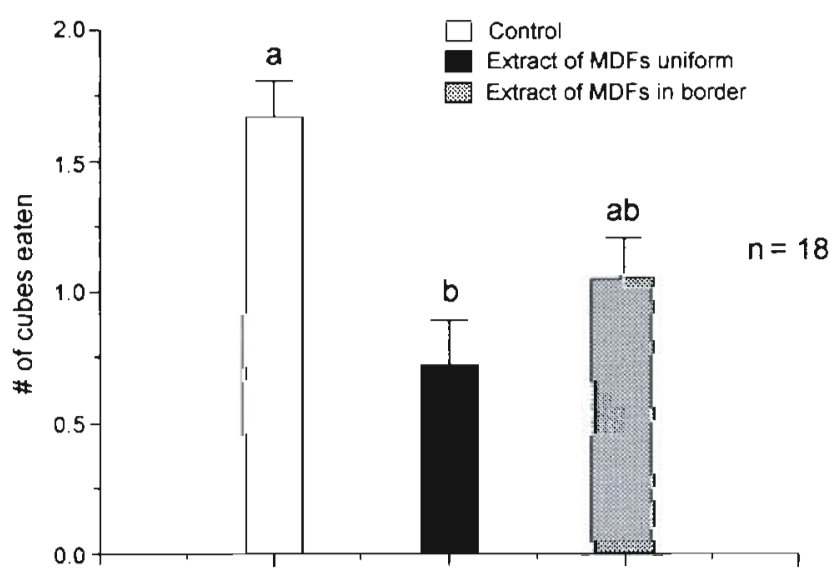

Fig. 7 Reef fish assay with squid cubes on ropes at Western Shoals (Apra Harbor, Guam). Squid cubes were prepared to include the extract of the secondary metabolites found in MDFs (a prepared muxture of scalaradial, deoxoscalarin, and desacetylscalaradial at realistic proportions determined by TLC). Control cubes contained only the solvent, whereas treatments contained the MDF mixture uniformly distributed into the cube or distributed only along one border. Bars indicate the number of cubes eaten (means $+S E$ ). Similar letters above the bars indicate means that did not differ significantly ( $p>0.05$, multiple comparisons for nonpasametric randomized block ANOVA by Tukey's procedure for ranked data) 
García et al. 1991, Avila 1993, Fontana et al. 1993, Avila \& Durfort 1996). While the role of the MDFs is not known, they are present in many chromodorid nudibranchs (Avila \& Durfort 1996). In addition to sequestering and concentrating defensive chemicals (García et al. 1990, Fontana et al. 1994a, this study), they may function in exocrine secretion (they are not glands with ducts to the surface but may exude their contents directly at the surface), or in mitigating autotoxicity.

The diet-derived compounds of Glossodoris pallida are selectively distributed in the nudibranch body and secretion (Table 1). Scalaradial, the main sponge compound, is accumulated in the mantle border where the MDFs are located, and is secreted in the mucus together with desacetylscalaradial, but is not present in the viscera. Deoxoscalarin is not found in the sponge and is probably transformed by the nudibranch, as suggested by Rogers \& Paul (1991). This compound is found in the reproductive system and eggs, and also in the border of the mantle. Our results support the proposed transformation of scalaradial into deoxoscalarin; however, none of the extracted animals contained scalaradial in the viscera. The absence of scalaradial and the small amounts of deoxoscalarin in the digestive gland do not support the idea that scalaradial is converted into deoxoscalarin in this gland. We suggest that the presence of scalaradial in the mantle border is due either to an immediate transport to the MDFs by an unknown mechanism while the nudibranchs feed on the sponge, or to a very fast transformation into deoxoscalarin and a retransformation into scalaradial in the MDFs.

Hypselodoris orsini is also able to transform scalaradial from its sponge prey into deoxoscalarin (Cimino et al. 1993). In this case, scalaradial is completely absent in the nudibranch, and deoxoscalarin is found in the viscera (which includes digestive gland, reproductive system, and hermaphroditic gland). Deoxoscalarin is further transformed in $H$. orsini to 6-keto-deoxoscalarin, found in the mantle border where MDFs are located. In Glossodoris palida, the chemical transformation could start in the same way, from scalaradial to deoxoscalarin, and then could continue with transformation back to scalaradial in the mantle border

The allocation of deoxoscalarin into the reproductive system/hermaphroditic gland and in the egg masses remains to be further investigated, as it could have a role in. reproduction or in protection of the egg mass. However, Rogers \& Paul (1991) found that egg masses, which contain deoxoscalarin, were rapidly eaten by reef fishes in the field. Similarly, the role of the third compound desacetylscalaradial is still unknown, although extracts containing both scalaradial and desacetylscalaradial effectively deterred feeding by reef fishes and crabs. Desacetylscalaradial (Fig 1d) was identified by comparison of its spectroscopic data with that reported in the literature (Yasuda \& Tada 1981) for the sponge Cacospongia scalaris from Japan. This potent cell growth inhibitor (Yasuda \& Tada 1981), was also found in Chromodoris youngbleuthi by Terem \& Scheuer (1986).

Nudibranch crude extract and scalaradial alone deterred feeding by the crabs at or below natural concentrations (Fig 4). Scalaradial was tested at whole body concentrations ( $2.5 \%$ dry mass) against crabs and found to be deterrent, but its real concentration is higher due to its selective accumulation in the border of the mantle (MDFs). In the mantle border, scalaradial may account for up to $14.6 \%$ of dry mass (Table 1 ). Scalaradial also acted as a deterrent to reef fish at $2.5 \%$ (Rogers \& Paul 1991), although different results were obtained at different experimental locations. Our assays with the mantle border mixture of spongederived compounds and the tissue itself showed that both were deterrent to reef fishes at or below natural concentrations (Figs. $6 \& 7$ ). Nudibranchs with their MDFs removed were significantly preferred over nudibranchs with MDFs intact in the field by several species of predatory reef fish (Fig. 5), and a similar trend was seen in the laboratory with Leptodius spp. crabs. The compounds in the mantle border (where MDFs are located) play a clear role in the defense of the nudibranch.

The design of the water-column test may not appear to have ecological relevance, but it provided important information about fish preferences based on the presence or absence of the mantle border Our data on the fish species that were able to eat frozen Glossodoris pallida with mantle border (Amblyglyphidodon curacao, Thalassoma lutescens, Cheilinus fasciatus, and Scarus spp.) agree with those previously reported for live $G$. pallida (Rogers \& Paul 1991). In that study, only wrasses were observed to eat $G$. pallida when they were dropped into the water column above the reef. Frozen nudibranchs do not exactly mimic live animals because they lack the ability to actively secrete mucus and they lack behavioral defenses such as curling up and retracting their gills when mouthed by predators. Nonetheless, our results with frozen nudibranchs fit within the range of susceptibilities of live G. pallida to predation $(0$ out of 10 animals eaten by fishes in aquari.um assays and 9 out of 10 animals eaten by wrasses in field assays; Rogers \& Paul 1991). We also observed differences in the willingness of fishes to consume nudibranchs in assays conducted on different days. These data support the observation that secondary metabolites may provide protection against some predators, but may be useless against a few putative predators such as wrasses (Thalassoma spp.) or very hungry predators. 
Our experiments to test the effect of different distributions (uniform or along the border) of both the chemical mixture from MDFs and fresh MDF tissue with artificial squid diet indicated that there was no difference in the effectiveness of these defenses, although both were deterrent when compared with the controls. We were not able to demonstrate that a localized concentration of the compounds was more important than a uniform distribution of compounds for defense. Nudibranch behavior and the imperfection of our 'artificial nudibranchs' may explain why there was no difference in deterrence for the cubes with tissue or extract of MDFs in the 'borders' treatment with respect to the 'inside' treatment. For instance, the borders treatment had extract or tissue along only one face of the cube, thus offering one bad-tasting face and other good-tasting faces to the fish, while live nudibranchs offer only the face with the MDFs to the predator because the foot is normally attached to the substrate. Alternatively, localizing compounds along the mantle border may not be more advantageous for defense but may provide other physiological advantages to the nudibranchs. For example, sequestering terpenes in the MDFs and locating them as far away as possible from the internal organs may help the nudibranchs avoid any toxic effects of these compounds while deriving an effective chemical defense against predators. Localizing compounds near the surface of the mantle may also facilitate their exudation into the mucus for chemical defense.

Both the distribution of particular metabolites in nudibranchs and the effects of nudibranch compounds as defenses against potential predators have been previously examined (Avila 1995 and references therein, Cronin et al. 1995), but this is the first time that the importance of both location and activity of the compounds has been examined simultaneously in relevant field and laboratory experiments. Glossodoris pallida localizes sponge-derived compounds in MDFs located at the borders of the mantle. These compounds are effective defenses against predation by reef fishes and crabs. When a thin strip of tissue containing the MDFs is removed, the nudibranchs become significantly more vulnerable to predators, illustrating the importance to the nudibranchs of these concentrated spots of defensive chemicals for avoiding predation.

However, our experiments also suggest that nudibranchs could be equally well protected by distributing their compounds evenly throughout their bodies, and that localization is not essential for defense but instead perhaps for other physiological purposes such as secreting chemically rich mucus or avoiding autotoxicity.

Acknowledgements. This research was supported by the National lnstitutes of Health (grants GM38624 and MBRS GM44796 to V.J.P.) and a Spanish Government Postdoctoral fellowship to C.A at the Marine Biological Laboratory, Woods Hole, MA 02543, USA. Thanks are due to John Starmer, Robert Thacker, Marc Slattery, Melany Puglisi, Scott Hughes and the technical staff at the UOG Marine Laboratory for their help during the field assays, as well as to Clay Carlson and PattyJo Hoff for sharing with us their knowledge of the local fauna. We are grateful to Michelle Kelly-Borges, Natural History Museum, London, for examining the Cacospongia sp. and providing a description of this sponge. Wilfred Lumbang assisted with the isolation of desacetylscalaradial and with the quantitative analyses. $M$. Slattery provided data on the protein content of the nudibranchs. Chuck Birkeland provided advice on statustical analyses, and Mikel Becerro, Michelle Kelly-Borges, John Spiers, Robert Thacker, and 3 anonymous reviewers provided helpful comments on earlier drafts of the manuscript. This is contribution no. 391 of the University of Guam Marine Laboratory

\section{LITERATURE CITED}

Avila C (1993) Sustancias naturales de moluscos opistobranquios: estudio de su estructura, origen y función en ecosistemas bentónicos. PhD thesis, University of Barcelona

Avila C (1995) Natural products from opisthobranch molluscs: a biological review. Oceanogr Mar Biol Annu Rev 33: $487-559$

Avila C, Cimino G, Crispino A, Fontana A, Gavagnin M, Ortea J, Vardaro RR (1990) Defensive strategies of Chromodondidae nudibranchs: origins, anatomical distribution and role of selected chemicals. 25th Eur Mar Biol Symp, Ferrara, Italy (Abstract)

Avila C, Cımıno G, Fontana A, Gavagnin M, Ortea J, Trivellone E (1991) Defensive strategy of two Hypselodoris nudibranchs from Italian and Spanish coasts. J Chem Ecol $17: 625-636$

Avila C, Durfort M (1996) Histology of epithelia and mantle glands of selected species of Doridacean mollusks with chemical defensive strategies. Veliger 39: 148-163

Carté B, Kernan MR, Barrabee EB, Faulkner DJ, Matsumoto GK, Clardy J (1986) Metabolites of the nudibranch Chromodoris funerea and the singlet oxygen oxidation products of furodysin and furodysinin. $\mathrm{J}$ Org Chem 51 $3528-3532$

Cimino G, De Rosa S, De Stefano S, Sodano G (1982) The chemical defense of four Mediterranean nudibranchs. Comp Biochem Physiol 73B:471-474

Cimino G, Fontana A, Giménez F, Marín A, Mollo E, Trivellone E, Zubia E (1993) Biotransformation of a dietary sesterterpenoid in the Mediterranean nudibranch Hypselodoris orsini. Experientia 49:582-586

Cimino G. Sodano G (1994) Transfer of sponge secondary metabolites to predators. In: van Kempen TMG, Braekman JC (eds) Sponges in time and space. Biology, chemistry, paleontology. A. A. Balkema, Rotterdam, p 459-472

Cronin G, Hay ME, Fenical W, Lindquist N (1995) Distribution, density, and sequestration of host chemical defenses by the specialist nudibranch Tritonia hamnerorum found at high densities on the sea fan Gorgonia ventalina. Mar Ecol Prog Ser 119:177-189

Faulkner DJ (1992) Chemical defenses of marine molluscs. In: Paul $V$ (ed) Ecological roles of manne natural products. Comstock Publishing Associates, Ithaca, p 119-163

Fontana A, Avila C, Martínez E, Ortea J, Trivellone E, Cimino $G$ (1993) Defensive allomones in three species of Hypselodoris from the Cantabrian Sea. J Chem Ecol 19:339-356

Fontana A, Giménez F, Marin A, Mollo E. Cimino G (1994a) 
Transfer of secondary metabolites from the sponges Dysidea fragilis and Pleraplysilla spinifera to the mantle dermal formations (MDFs) of the nudibranch Hypselodoris webbi. Experientia 50:510-516

Fontana A, Trivellone $E$, Mollo $E$, Cimmo G, Avila $C$, Martinez E, Ortea J (1994b) Further chemical studies of Mediterranean and Atlantic Hypselodoris nudibranchs: a new furanosesquiterpenoid from Hypselodoris webbl. J Nat Prod 57:510-513

Garcia JC, Cimino G, Medina A (1990) Studies on the defensive behavior of Hypselodoris: ultrastructure and chemical analysis of mantle dermal formations (MDFs). Mar Biol 106:245-250

Garcia JC, Medina A, Covenas R (1991) Study on the anatomy and histology of the mantle dermal formations (MDFs) of Chromodors and Hypselodoris. Malacologia 32:233-240

Gavagnin M, Vardaro RR, Avila C, Cimino G, Ortea J (1992) Ichthyotoxic diterpenoids from the Cantabrian nudibranch Chromodoris luteorosea. J Nat Prod 55:368-371

Karuso P (1987) Chemical ecology of the nudibranchs. In: Scheuer PJ (ed) Bioorganic marine chemistry, Vol 1 Springer Verlag, New York, p 31-60

McClintock J, Baker BJ, Slattery M, Heine JN, Bryan PJ, Yoshida W, Davies-Coleman MT, Faulkner DJ (1994) Chemical defense of common Antarctic shallow-water nudibranch Tritoniella bella Eliot (Mollusca: Tritonıdae) and its prey, Clavularia frankliniana Rouel (Cnidaria: Octocorallia). J Chem Ecol 20:3361-3372

Pau VJ, Lindquist N, Fenical W (1990) Chemical defenses of the tropical ascidian. Atapozod sp. and its nudi branch predators Nembrotha spp. Mar Ecol Prog Ser 59:109-118

Paul VJ, Pennings SC (1991) Diet-derived chemical defenses in the sea hare Stylocheilus longicauda (Quoy et Gaimard, 1824). J Exp Mar Biol Ecol 151:227-243

Paul VJ, Van Alstyne KL (1988) Use of ingested algal diterpenoids by Elysia halimedae Macnae, as antipredator defenses. J Exp Mar Biol Ecol 119:15-29

Pawlik JR, Kernan MR, Molinskı TF, Harper MK, Faulkner DJ (1988) Defensive chemicals of the Spanish dancer nudibranch Hexabranchus sanguineus and its egg ribbons:

This article was presented by C. Burkeland (Senior Editorial Advisor), Mangilao, Guam macrolides derived from a sponge diet. J Exp Mar Biol Ecol 119:99-109

Pennings SC (1994) Interspecific variation in chemical defenses in the sea hares (Opisthobranchia: Anaspidea). J Exp Mar Biol Ecol 180:203-219

Pennings SC, Pablo SR, Paul VJ, Duffy JE (1994) Effects of sponge secondary metabolites in different diets on feeding by three groups of consumers. J Exp Mar Biol Ecol 180: $137-149$

Peterson CH, Renaud PE (1989) Analysis of teeding preference experiments. Oecologia 80:82-86

Rogers CN, Steinberg PD, de Nys R (1995) Factors associated with oligophagy in two species of sea hares (Mollusca: Anaspidea). J Exp Mar Biol Ecol 192:27-73

Rogers SD, Paul VJ (1991) Chemical defenses of three Glossodoris nudibranchs and their dietary Hyrtios sponges. Mar Ecol Prog Ser 77:221-232

Ros J (1976) Sistemas de defensa en Ios opistobranquios. Oecol Aquat 2:41-77

Rudman WB (1984) The Chromodorididae fOpisthobranchia: Molluscaj of the Indo-West Pacific: a review of the genera. Zool J Linn Soc 81:115-273

Rudman WB (1985) The Chromodorididae (Opisthobranchra: Molluscal of the Indo-West Pacific: Chromodoris aureomarginata, C. verneri and C. fidelis colour groups. Zool J Linn Soc 83:241-299

Terem B, Scheuer PJ (1986) Scalaradial derivatives from the nudibranch Chromodoris youngbleuthi and the sponge Spongia oceanica. Tetrahedron 42:4409-4412

Thompson JE, Walker RP, Wratten SJ, Faulkner DJ (1982) A chemical defense mechanism for the nudibranch Cadlina luteomarginata. Tetrahedron 38:186j 1873

Van Alstyne KL, Wylie CR, Paul VJ, Meyer K (1992) Antipredator defences in tropical Pacific soft corals $1 \mathrm{Coe}$ lenterata: Alcyonacea). I. Sclerites as defenses against generalist carnivorous fishes. Biol Bull 182:231-240

Yasuda F, Tada H (1981) Desacetylscalaradial, a cytotoxic metabolite from the sponge Cacospongia scalaris. Experientia 37:110-111

Zar JH (1984) Biostatistical analysis, 2nd edn. Prentice Hall Inc, Englewood Cliffs, p 230-231

Manuscript first received: June 18, 1996

Revised version accepted: February 24, 1997 